From the Centre of Cardiology, Dr. Cipto Mangunkusumo Hospital, Medical School, University of Indonesia, Jakarta.

\title{
Patent Ductus Arteriosus (P.D.A.) (An analysis of 37 surgically proved cases)
}

by

O.J. RACHMAN, A. HANAFIAH and I.S.F. RANTI.

An analysis of the clinical picture on 37 cases of patent ductus arteriosus proved by operation is presented, including the chest $X$-ray and electrocardiographic findings.

In 13 cases preoperative hemodynamic studies were necessary to establis/2 the diagnosis, although in most of the cases it could be based on clinical findings only.

During the years 1968 to 1973, 37 patients were operated upon for patent ductus arteriosus (PDA) at the Cardiologic Center, Dr. Cipto Mangunkusum, Hospital, Medical School University of Indonesia, Jakarta.

This paper is meant to analyse the clinical picture and in some instances, the hemodynamic findings of those 37 patients.

Received 11th. Sept. 1974. 


\section{Materials and methods}

The records of 37 patients with the diagnosis of simple patent ductus arteriosus who were operated on during the years 1968 to 1973 were reviewed concerning the age, sex, symptoms and physical examination findings. Preoperative ECG's were also reviewed. When more than one ECG were available the one closest to the date of surgery was analysed.

The criteria for ventricular hypertrophy were those of Ziegler (1951) for patients up to 15 years and Goldman (1970) for older patients. Preoperative chest X-ray's were reviewed for cardiothoracic ratio, the presence of pulmonary artery segment prominence and for increased pulmonary vascular markings. The results of catheterization which were done on 13 patients, were also reviewed.

\section{Results}

The ages of the patients were between 1 and 33 years; 2 patients were one year old, 11 were between $1-5$ years, 15 were between $5-15$ years and 9 were older than 15 years. Twenty-nine of those 37 patients (75\%) were female.

\section{History}

Seventy-eight percent of the patients revealed a history of frequent respiratory tract infections. Becoming easily fatigued was noted in $48 \%$ of the patients.
Three patients $(8 \%)$ whose ages were 25,28 and 33 years respectively, complained of palpitation; 2 of them were accompanied by angina pectoris and 1 patients was accompanied by lightheadedness which was probably caused by frequent multifocal ventricular extrasystole.

Overt heart failure occurred in 2 patients, both were younger patients, $11 / 2$ and 2 years old respectively, with recurrent respiratory tract infections. A history of subacute bacterial endocarditis was noted in 2 patients.

Three patients had also a history of bronchial asthma. One patient with oligophrenia had been operated upon previously for congenital cataract. A history of rash during the first trimester of pregnancy was elicited from the mother, suggestive of rubella infection. In 2 patients there were no complaints; cardiac abnormalities were suspected on routine physical examination.

\section{Physical findings}

Of 28 patients up to the age of 15 years, $15(53 \%)$ had preoperative body weights below the average body weight of Indonesian children as measured by de Haas et al. (193'7, 1940) (Figure 1). Auscultatory blood pressure which was taken in 35 patients revealed a pulse pressure of more than $50 \mathrm{~mm} \mathrm{Hg}$ in $17 \mathrm{pa}$ tients $(49 \%)$, recorded as celer, collapsing or bounding pulse. Voussoure 
cardiaque was present in 10 patients $(26 \%)$. Thrill was felt in 31 patients $(83 \%)$ usually on the pulmonary area, in some instances it was also felt on the left infraclavicular area, suprasternal or left sternal border.

Accentuated pulmonary component of the 2n'd heart sound was heard in 18 patients $(48 \%)$. In the other patients the 2nd heart sound was neither accentuated nor overshadowed by the murmur. The 3rd heart sound was heard in 4 patients $(10 \%)$.

In 33 patients $(89 \%)$ a continuous murmur was heard on the pulmonary area. In most cases it is radiated also to the infraclavicular area, lefi sternal border, apex or to the back. A systolic murmur which was more pansystolic in type was also heard on the lower left sternal border in 2 of them and on the apex in 2 patients with nearly the same intensity as the continuous murmur. In 3 other patients the murmur was systolic and early diastolic in character resembling a to and fro murmur of aortic insufficiency. In one patient the murmur was heard only in the systolic phase without any continuation into the diastolic phase and was heard on the pulmonary area. Mid-diastolic flow murmur on the apex was heard in 8 patients $(21 \%)$.

\section{Chest X-ray}

There were 38 chest X-ray's available for review. In 25 patients (67\%) the cardiothoracic ratio was more than $50 \%, 15$ of which $(41 \%)$ was greater than $60 \%$.

Pullmonary artery segment prominence was observed in 23 patients $(63 \%)$. Increased pulmonary vascular markings were observed in all except 3 patients (Figures 2 and 3 ).

\section{Electrocardiogram}

There were 35 preoperative Electrocardiograms available for analysis. In 32 patients $(91 \%)$ the frontal QRS axis were normal, the other 3 patients showed deviation of the QRS frontal axis to the right. Vertical or semi-vertical heart positions was noted in 26 patients $(74 \%)$ and in 9 others the electrical heart position was intermediate. Signs of left atrial enlargement presenting as notched $P$ waves was present in 11 patients (31\%).

Twenty-four patients (66\%) showed signs of ventricular hypertrophy, 10 of which showed left ventricular hypertrophy, 2 showed right ventricular hypertrophy and 12 with signs of biventricular hypertrophy. In 11 patients (31\%) the ECG showed no signs of ventricular hypertrophy (Figure 4).

Upward concavity of the S-T segment was present in 22 patients (62\%) mostly in leads II, III, aVF and V4-V6 (Figure 5).

\section{Catheterization}

Catheterization which was done on 13 patients showed oxygen saturat- 
ion step up between right ventricle and pulmonary artery of 7 to $33 \%$ (see Table 1). Pulmonary artery systolic pressure more than $20 \mathrm{~mm} \mathrm{Hg}$ in 10 patients, two of which nearly equalized the systemic pressure (98 and $132 \mathrm{~mm} \mathrm{Hg}$ ). Direct catherization of the ductus was possible in 7 instances (Figure 6). Aortic root contrast injection which simultaneously opacified the pulmonary artery was done in 3 instances.

\section{Discussion}

Patent ductus arteriosus is a congenital malformation due to failure of the closure of the ductus arteriosus in the neonatal period. The diagnosis is usually easy in most of the cases due to the presence of a continuous murmur characterized by a crescendo decrescendo murmur with its peak around the second heart sound. A widened pulse pressure is usually observed, largely due to decreased diastolic pressure.

In some instances patent ductus arteriosus gives no characteristic continuous murmur on auscultation, usually due to the absence of the diastolic component of the murmur, or it can resemble the murmur of aortic insufficiency.

Figure 7 showed the relationship between murmur, mean pulmonary artery pressure and ECG in 11 patients. Most of the patients with continuous murmur had a lower mean pulmonary artery pressure. In
2 patients with mean pulmonary artery pressure of 62 and $108 \mathrm{~mm}$ $\mathrm{Hg}$, the murmur was systolic in one and systolic/early diastolic in the other. This early diastolic murmur could also be caused by pulmonary insufficiency although Cruze et al. (1963) in one case found that the early diastolic murmur, which was louder than the systolic component, promptly disappeared after surgery.

Electrocardiograms of these 2 patients showed an isolated right ventricular hypertrophy pattern. Ziegler (1952) stated that isolated right ventricular hypertrophy is rare in patent ductus arteriosus and he observed that even when pulmonary arterial pressure was markedly increased the electrocardiogram showed left rather than right ventricular hypertrophy. Other observation by Rudolph et al. (1958) in patients below the first year of life showed that right ventricular hypertrophy was associated with elevated mean pulmonary artery pressure compared with those of biventricular hypertrophy or left ventricular hyper. trophy.

Notching of the $P$ wave suggestive of some enlargement of the left atrium was sometimes noted in electrocardiograms of patent ductus arteriosus. Keith et al. (1967) found this phenomenon in $5 \%$ of cases with left ventricular hypertro'phy and in other $5 \%$ without associated left ventricular hypertrophy. 
Among 11 of our cases with electrocardiograms presenting this sign $(31 \%)$ only 4 were associated with left ventricular hypertrophy. This is also in accordance with the findings of Ziegler (1952) that there was no correlation between left atrial enlargement and left ventricular hypertrophy in patent ductus arteriosus.

Upward concavity of the S-T segment which was usually seen in leads II, III, aVF and left precordial leads was found in $62 \%$ of our cases. This is nearly the same percentage as observed by Krovetz and Warden (1962) in their cases over one year of age. Probably this would be a useful sign in suspecting the presence of patent ductus arteriosus since it was found in only $2 \%$ of other congenital heart diseases (Krovetz and Warden, 1962). Abnormalities founä on chest X-ray offered no diagnostic specificity in patent ductus arteriosus. Cardiac enlargement, prominence of pulmonary artery segment and increased vascular markings could also be present in other intracardiac left to right shunt.

In most of the cases reported here the diagnosis of patent ductus arteriosus was suspected from clinical findings only. However, sometimes it was necessary to make further examinations if the clinical findings were doubtful or because other concomitant intracardliac abnormalities were suspected.
Catheterization in this situation could establish the diagnosis by way of :

1. measuring the oxygen saturation step up between right ventricle and pulmonary artery

2. direct catheterization of the ductus in which the catheter enters the aorta from the pulmonary artery via the ductus

3. injection of the contrast into the root of the aorta will simultane. ously opacify the pulmonary artery or delineate the ductus itself

4. recording the pressure in the pulmonary artery and the right ventricle to determine the prognosis.

The symptoms in patent ductus arteriosus can be very minimal or markedly incapacitating, usually in the extremes of age (Campbell, 1955; Gross, 1952; Keith et al., 1967; Krovetz and Warden, 1962). Most of the authors recommend closure of the patent ductus arteriosus, unless there is a contraindication.

Although there are reports on the occurrence of delayed spontaneous closure up to 8 months especially in premature infants (Danilowics et al., 1966) and respiratory distress syndrome (Auld, 1966), it seems that this occurrence is probably rare. In symptomatic patients the operation should be done as soon as the diagnosis is established. In asymptomatic patients the operation could be dcferred, preferably before school age. 
There was one death in our ope. rated cases, due to septic shock caus. ed by infection of the middle ear.
Better preoperative management could probably have avoided this complication.

\section{REFERENCES}

1. AULD, P.A.M. : Delayed closure of the ductus arteriosus. J. Pediatr. 69 : 61 (1966).

2. CAMPBELL, M. : Patent ductus arteriosus. Some notes on prognosis and pulmonary hypertension. Br. Heart .T. 17 : 511 (1955).

3. CRUZE, K., ELLIOT, L.P., SCHIEB. LER, G.L. and WHEAT, M.W.: Unusual manifestations of patent ductus arteriosus in infancy. Dis. Chest 43 : 563 (1963).

4. DANILOWICS, D., RUDOLPH, A.M. and HOFFMAN, J.I.E. : Delayed closure of the ductus arteriosus in pre. mature infants. Pediatrics $37: 74$ (1966).

5. DE HAAS, SUKOMTO and TAN ENG DONG; and DE HASS and GORTER : Daftar berat badan anak 1932 - 1937 dan 1935 - 1940 in Kumpulan Kuliah Ilmu Kesehatan Anak Fak. Kedokteran Univ. Indonesia, 1st edition pp. 503 -. 504 (1968).

6. GOLDMAN, M.J.: Principles of clinical electrocardiography. 7 th ed. (Lange Medical Publ., San Francisco 1970).
7. GROSS, R.E. : The patent ductus arteriosus. Observations on diagnosis and therapy in 525 surgically treated cases. Am. J. Med. $12: 472$ (1952).

8. KJITH, J.D., ROWE, R.D. and VLAD, P. : Heart disease in infancy and childhood. 2nd ed. pp. $162-212$ (MacMillan, New York 1967).

9. KROVETZ, L.J. and WARDEN, H.E.: Patent ductus arteriosus. An analysis of 515 surgically proved cases. Dis. Chest 42 : 46 (1962).

10. RUDOLPH, A.M., MAYER, F.E., NA DAS A.E. and GROSS, R.E. : Patent ductus arteriosus. A clinical and hemodynamic study of 23 patients in the first year of life. Pediatrics 20 : 892 (1958).

11. ZIEGLER, R.F.: The importance of patent ductus arteriosus in infants. Am. Heart J. $43: 553$ (1952).

12. ZIEGLER, R.F.: Electrocardiograplic studies in infants and children. (Charles Thomas Publ., 1951) cited from Keith et al. (1967). 


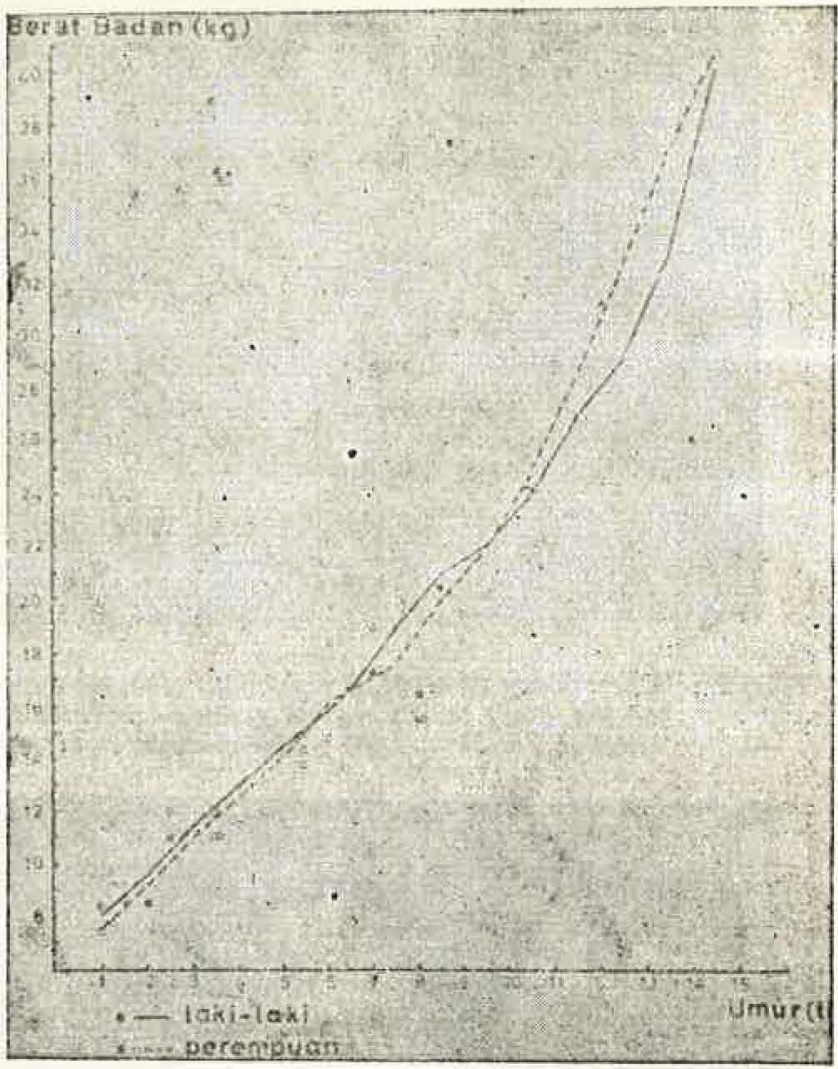

FIG. 1 : Body weights of 28 patients up to the age of 15 years compared to the average body weight of Indonesian children (see text).

abscissa : age (years), ordinate : body weight (kg), closed and open circles are body weights of male and female patients.

solid and broken lines represent. the average body weight of male and female Indonesian children (de Haas et al.). 